\title{
A systematic analysis of a two-word concgram in Nepalese policy documents: A corpus-driven approach
}

\author{
Madhu Neupane Bastola, \\ Tribhuvan University, Nepal
}

\begin{abstract}
Corpus linguistics can inform language teaching in various aspects from syllabus designing to creating exercises based on the real use of language. However, its use in language teaching is still rare. In the context of Nepal, though corpus linguistics forms a part of the University Curriculum in English Education, the students are rarely offered a practical experience of corpus analysis. The same is the case with teacher training courses. This paper followed an analytical procedure for identifying phraseological variation within a two-word 'concgram' that is a set of co-occurring words. In this paper, a two-word concgram, make/effort, is analyzed to identify concgram configurations, the most frequently used form, and its meaning by using concordance lines. Lastly, the paper presents the implications of corpus analysis in English language teaching.
\end{abstract}

Keywords: Corpus, ConcGram, concgrams, phraseology, meaning shift units

\section{Introduction}

In a general sense, a corpus refers to a collection of texts. More specifically, a corpus is a collection of naturally occurring machine-readab-le discourse put together for linguistic research (Adolphs, 2006; McEnery \& Hardie, 2012) and the area of linguistics that studies a corpus is corpus linguistics. Corpus linguistics has been informed by empiricism as its philosophical base for the study of language (Adolphs, 2006; Aijmer, 2009; McEnery \& Hardie, 2012; Sinclair \& Carter, 2004; Stubbs, 2005, 2007) for making sense of naturally occurring language data (Tognini-Bonelli, 2001). It has been a fertile field of research because it has a broader application in different areas such as language teaching, professional communication, and academic writing, to name but three. Based on the nature and purpose of research, corpus research has been divided into three types: corpus-based, corpus-driven, and data-driven (Adolphs, 2006; McEnery \& Hardie, 2012; Rayson, 2008; Tognini-Bonelli, 2001) 
Corpus-based research is mostly top-down because it usually explores the relationship between theory and data. According to Tognini-Bonelli (2001), researchers following this approach usually start with a predefined model of language or hypotheses about language and "analyse the corpus through these categories and sieve the data accordingly" (p.66). As the researchers are interested in how well their theories are accounted for by data, a theory is a priori to corpus-based research. This deductive methodology can sometimes cause a problem when the data does not fit to theory because of the inherent variability in language. Such problem may lead the researchers either to modify the theory or to insulate the data that fits the theory (Tognini-Bonelli, 2001). Nevertheless, corpus-based studies are common in second language acquisition because findings derived from such studies can be helpful in teaching-learning processes (Aijmer, 2009).

Unlike in corpus-based approach, in a corpus-driven approach, a corpus "is seen as more than a repository of examples to back pre-existing theories or a probabilistic extension to an already well-defined system. The theoretical statements are fully consistent with and reflect directly, the evidence provided by the corpus" (TogniniBonelli, 2001, p. 84). The researchers use their knowledge to make sense from the data. This approach is inductive and takes a holistic stance in describing the system of language by using uncontaminated (i.e., not pre-tagged) raw data (Sinclair \& Carter, 2004). Because of its holistic nature, corpus-driven research gives high priority to the representativeness of corpus to derive valid conclusions and emphasizes a continuous update of a corpus (Sinclair \& Carter, 2004; Tognini-Bonelli, 2001). However, there is no fixed size for a sample to be representative. The appropriateness of the size depends on the claims that the researchers want to make.

In addition to corpus-based and corpus-driven approaches, Rayson (2008) proposes a data-driven approach, which, he claims, combines both corpus-based and corpusdriven research approaches. Unlike a corpus-based approach, the data-driven approach does not start with research questions instead starts with building a corpus. Then it goes on to annotate the corpus, retrieve data from the corpus, devise a research model or questions, retrieve data, and interpret the data for confirming the hypothesis. Though this model is similar to the corpus-driven method as it starts with building a corpus, it uses part of speech tagging commonly used in corpus-based studies. This study followed a corpus-driven approach to explore a corpus of Nepalese policy documents.

\section{Phraseology and meaning shift units (MSUs)}

Phraseology is the study of the structure of phraseological units referred differently as phrseologism (Gries, 2008), multiword sequences such as "lexical phrases, formulas, routines, fixed expressions, prefabricated patterns (or prefabs), and lexical items" (Biber, Conard, \& Cortes, 2004) or meaning shift units (MSUs) (Cheng, Greaves, Sinclair, 
and Warren, 2009). According to Cheng et al. (2009), phraseology is used "in an inclusive sense to describe the tendency for words to be co-selected by speakers and writers to achieve meanings" (p. 236). Sinclair (2004) refers to this tendency as the 'idiom principle' because the choice of one word greatly constraints the other choices available.

Different terms (e.g., n-grams, multiword expressions, skip grams, phrase frames, phraseologism, or MSUs) are used to refer to phraseological units. Among them, phraseologism and MSUs are more convincingly defined. A phraseologism refers to:

the co-occurrence of a form or a lemma of a lexical item and one or more additional linguistic elements of various kinds which functions as one semantic unit in a clause or sentence and whose frequency of co-occurrence is more significant than expected by chance. (Gries, 2008, p. 6)

This definition focuses on six different aspects in defining a phraseologism: the nature of the element (i.e., a lexical item or a grammatical unit), number of elements (two or more), frequency of occurrence (more than that can occur by chance), distance (contiguous or non-contiguous), flexibility (fixed or variable), and semantics (functioning as a semantic unit in terms of meaning). From this perspective, in spite of and of course are examples phraseologisms (Gries, 2008).

Sinclair (2004) used the term MSU to describe meaningful word associations. The basic idea behind using the term MSU is that "each new combination of words generates a shift in meaning, even if this is only relatively subtle, compared with other possible combinations involving one or more of the words" (Cheng et al., 2009, p. 237). In each collection of words, there is a shift in meaning. For example, in the unit hard work the meanings of hard and work have shifted to give a new sense. The meaning of hard in hard work differs from the meaning of hard in hard surface. The meaning of hard in these examples shifts as it combines with different words. According to Cheng et al. (2009), an MSU is composed of five categories of co-selection: the core (the element that is invariably present), semantic prosody (negative or positive orientation of meaning), semantic preference (restriction to regular co-occurrence), collocation (content words that usually co-occur with the core), and colligation (grammatical categories that usually co-occur with the core). Out of these five categories of co-selection, the core and semantic prosody are obligatory while others are optional. The analysis of a concgram make effort illustrates all these aspects of co-selection.

Implicitly subsumed in the definition of an MSU are the criteria of distance between elements (i.e., contiguous or non-contiguous), their flexibility or positional variations (e.g., hard work and work hard), and their frequency of occurrence in a corpus. Therefore, the definition of an MSU is more comprehensive as it incorporates all the defining aspects of a phreseologism discussed above and more. Therefore, this paper uses the 
concept of MSU in analyzing word associations and uses ConcGram@ (Greaves, 2009) program to identify such associations fully automatically.

\section{ConcGram and concgrams}

Examining the association between words has been an important area of study (Greaves \& Warren, 2007) yet a difficult task (Cheng, Greaves, \& Warren, 2006) in corpus linguistics. Previous research on extracting word association has focused on n-grams (i.e., contiguous words that constitute a phrase such as a lot of people) and skipgrams (i.e., non-contiguous word associations that are four words apart-e.g. play a much less important role). However, neither n-grams nor skipgrams can extract positional variations in word associations such as role play and play a role (Cheng et al., 2006). A new computer-mediated software ConcGram@ (Greaves, 2009) has overcome this problem as it can automatically identify all the potential configurations of between 2 and 5 words including positional variations (e.g. work hard and hard work) and constituency variations (i.e., work hard and work very hard) (Cheng et al., 2009, 2006; Greaves \& Warren, 2007). Such associations between words with the constituency and/or positional variations are called concgrams. In other words, concgrams are "co-occurring words irrespective of whether or not they are contiguous, and irrespective of whether or not they are in the same sequential order" (Cheng et al., 2009, p. 237). As in other corpus research software such as WordSmith (C) (Scott, 2012), concordance lines are used in ConcGram. Interestingly though, ConcGram highlights all the associated words of a concgram in each concordance line as shown in the following examples:

\footnotetext{
the concerned corporation will be required to make efforts to control its cost of production or the situation Teachers were found to have made some efforts to address the language problems concrete steps in that direction. The plan will make all possible efforts in this regard. The limited availability of sources and means have made our planned development efforts more training local leaders and social workers to make them more responsive to development efforts. economic policies, it becomes a national duty to make available some returns of development efforts inflow of information or conservation effortsmade in the international context and to mobilize is, therefore, essential that further efforts be made to ensure a multi-purpose development and use of been the case in the past, then efforts will be made to promote highly essential industries from among plans in future. Hence, efforts are to be made further for extending various educational will be strengthened. Efforts will also be made to coordinate the research and development education. (3) Efforts should be continued to make Sanskrit education timely, socially beneficial efforts for industrial development have been made in preceding years, even with the mentioned
}

There can be two-, three-, four-, or five-word concgrams. Identification of concgrams helps us to better understand idiomatic nature of language by observing the coselection pattern in a spoken or written discourse. The search for concgrams can be automatic or user nominated. ConcGram is corpus-driven as it extracts the concgrams fully automatically (refer to Cheng et al., 2006, Cheng et al., 2009 or Greaves \& Warren, 2007 for more information about the process). The ConcGram software identifies all the co-occurrences of words that comprise a concgram. The researchers need to identify the associated ones and discard others because some of such co-occurrences shown 
in concordance lines may not be associated (Cheng et al., 2009). The co-occurrences of make and effort in the following examples are not associated:

efforts, the country has not been able to makeany significant progress in raising domestic

efforts to their sustainable development and to make them capable by their participation. Organisation

This paper analyzes one of the most frequent two-word concgrams make effort in a Nepalese Policy Corpus (NPC hereafter) of about two million words and identifies all possible concgram configurations and configuration functions.

\section{The present study}

This research aimed to examine one of the most frequently occurring congrams (i.e. make effort) with positional variation in the NPC. For this purpose, first, the corpus of Nepalese Policy documents consisting of 11 periodic plans (1956-2016), 9 educational plans (1956-2016), 3 constitutions (1990-2015), and two language policy documents (1990-2016) was created by combining the soft copies of these documents available various websites. The corpus has around 2 million words. Second, from the NPC, the lists of unique words and two-word congrams excluding function words were generated. One of the most frequently occurring two-word concgrams (i.e., make effort) with both constituency variation (e.g., make efforts, make great efforts) and positional variation (e.g., make effort and efforts made) was chosen for further analysis informed by Cheng et al.'s (2009) framework. Third, concordance lines for the selected concgram were generated by using ConcGram $\odot$ (Greves, 2009) because of its robust nature in extracting phraseological units that have positional variations as well constituency variations (Cheng et al., 2009; Warren, 2009). Wild card and word/prefix functions were used in the search process to identify all inflectional variations of make (i.e., make, made, making, makes) and effort (i.e., effort and efforts) (see Greves, 2009 for more information about the use of wild clad and word/prefix function). The concordance generated 459 co-occurrences of make effort in the corpus. Out of them, 22 cooccurrences were excluded from the analysis because they did not belong to the same MSU that is make effort. Nine of the co-occurrences were generated because of the use of wild card and word/ prefix functions used in the search process:

location. The NASA is a tool that decision makers can use to target efforts and resources for are delayed because of shortage of construction materials, and duplication of effort occurs. Limited

In thirteen of them, two words (i.e., make and effort) were not associated:

for their gradual utilisation will be made. Other Means of Transport · Efforts to link the improved. Institutional reforms will be made to make co-operative movement effective. Efforts will

Therefore, altogether there were 437 instances (make effort- 45 and effort made-392) of the concgram make effort in the NPC. The MSUs and the canonical concgram configuration and functions were identified keeping two factors into consideration: whether or not the concgram units belonged to the same MSU and how frequently 
they occurred in the corpora. The canonical function related to the canonical form and degrees of turbulence (i.e., variation in a canonical form) were also identified. WordSmith $\odot$ (Scott, 2012) was used to examine collocation and colligation of the word effort.

Finally, to better understand the use of the concgram, the findings obtained from the NPC were compared with other reference corpora, Brown corpus, Frieburg-Brown Corpus, London-Oslo/Bergen Corpus, and Frieburg-London-Oslo/Bergen Corpus. The reference corpora are briefly described in this section.

Brown corpus (BC): Brown corpus is 1-million-word corpus of standard American English complied by W.N. Francis and H. Kucera at Brown University in 1961. The corpus was named after Brown University. The texts for the corpus were sampled from 15 different text categories. The corpus contains 500 texts of just over 2000 words. (https://www1.essex.ac.uk/linguistics/external/clmt/w3c/corpus_ling/ content/corpora/list/private/brown/brown.html)

Frieburg-Brown (Frown)Corpus (FC): Frown corpus was compiled by Christian Mair. It matches the Brown corpus in its design but was compiled to represent American Standard English of the early 1990s. It was named after University of Freiburg, Germany. (http://clu.uni.no/icame/manuals/FROWN/INDEX.HTM)

London-Oslo/Bergen Corpus ( $\mathrm{LOB}$ corpus): The LOB corpus was prepared with the cooperation between the University of Lancaster, the University of Oslo, and the Norwegian Computing Centre for the Humanities at Bergen. It is like Brown corpus in design and sample (i.e., fifteen different text categories and 500 printed texts of just over 2000 words). However, unlike Brown corpus, it represents standard British written English of the 1960s (http://clu.uni.no/icame/lob/lob-dir.htm).

Frieburg-London-Oslo/Bergen (FLOB) Corpus: This corpus is also a member of brown family. Designed by Christian Mair in 1991, the corpus matches the well-known Brown and LOB corpora and represents standard written British English of the early 1990s (http://clu.uni.no/icame/manuals/FLOB/INDEX.HTM).

Hong Kong Financial Service Corpora (HKFSC): HKFSC is a 7-million-word corpus of collection of text from Hong Kong financial service. It was developed by the Research Centre for Professional Communication in English of The Hong Kong Polytechnic University (http://rcpce.engl.polyu.edu.hk/HKFSC/). 


\section{Results and discussion}

\section{Analysis of the first positional variation of the concgram (i.e., make effort)}

Among the 437 instances of the concgram, there were 45 instances of the first positional variation (i.e., make effort). The different configurations of the variation are presented in Table 1.

Table 1. The configurations of the first positional variation in the NPC

\begin{tabular}{|c|l|c|}
\hline S.N. & make/effort & Frequency \\
\hline 1. & make effort & 11 \\
\hline 2. & make*effort & 22 \\
\hline 3. & make $^{* *}$ effort & 11 \\
\hline 4. & make $^{* * *}$ effort & 1 \\
\hline
\end{tabular}

The data shows that make *effort (with one word in between) had the highest frequency of occurrence (22 times). This most frequently occurring form is the canonical form. The canonical form has either determiner (7 times) or a modifier (13 times) as the intervening word. The second most frequent configurations were make effort (11 times) without any Note: The number of * refers to the number of intervening word and make**effort (11 words between make and effort. times) with two intervening words. The followings are some representative examples of the different configurations of make effort in the NPC:
market and production provision and to makeefforts to move ahead to cope international The University and its colleges should make no effort to mould high school curricula to to this, the National Planning Commission has made an effort to incorporate the suggestions received essential for the programmes of all sectors to make a concerted effort to alleviate poverty. Hence, limited availability of sources and means have made our planned development efforts more

The configurations of make effort obtained from the NPC were compared with those obtained from the reference corpora described in the previous section. The results are shown in Table 2.

Table 2. The comparisons of the configurations of the first positional variation

\begin{tabular}{|l|c|c|c|c|}
\hline $\begin{array}{c}\text { make } \\
\text { effort }\end{array}$ & $\begin{array}{c}\text { make } \\
\text { effort }\end{array}$ & $\begin{array}{c}\text { make* } \\
\text { effort }\end{array}$ & $\begin{array}{c}\text { make** } \\
\text { effort }\end{array}$ & $\begin{array}{c}\text { make*** } \\
\text { effort }\end{array}$ \\
\hline BC & & 2 & 3 & 1 \\
\hline FC & & 7 & 3 & \\
\hline LOBC & & 6 & 2 & 1 \\
\hline FLOBC & & 7 & 2 & \\
\hline HKFSC & 3 & 38 & 13 & 4 \\
\hline NPC & 11 & 22 & 11 & 1 \\
\hline
\end{tabular}

Note: The number of * refers to the number of words between make and effort. 
The comparison also shows that make effort is the canonical configuration with its highest frequency of occurrence. Unlike in the NPC, the configuration make effort without any intervening word was nonexistent in reference corpora except in HKFSC. Table 3 presents the configuration functions of the first positional variation.

Table 3. The configuration functions of make/effort in the NPC

\begin{tabular}{|l|l|l|}
\hline S.N. & \multicolumn{1}{|c|}{ make effort } & Frequency \\
\hline 1. & Verb + object & 11 \\
\hline 2. & Verb + det. /mod. + object & 22 \\
\hline 3. & Verb + det. /mod. + mod. + object & 11 \\
\hline 4. & Verb + det. + mod. + mod. + object & 1 \\
\hline
\end{tabular}

In the configurations outlined in Table 3 , make functions as a verb and effort (s) as an object. In eleven of these cases, verb and object are contiguous and, in 22 cases, there was a single intervening word (either a determiner or a modifier). In rest of the cases, there were two or three intervening words. In some cases, the intervening words were determiners and modifiers (e.g., a concerted effort) or two modifiers (e.g., poverty alleviation efforts). The words like special, coordinated, concerted, and possible modified the word effort. The configuration function with either one determiner or one modifier was the most frequent one.

The reference corpora were examined to compare the configuration functions of the first positional variation as identified in the NPC. The comparison confirmed the findings obtained from the NPC (see Table 4).

Table 4. The configuration functions of make/effort in the reference corpora

\begin{tabular}{|l|c|c|c|c|}
\hline & Verb + object & $\begin{array}{c}\text { Verb + det. /mod. }+ \\
\text { object }\end{array}$ & $\begin{array}{c}\text { Verb + det. /mod. + mod. + } \\
\text { object }\end{array}$ & Other \\
\hline BC & & 8 & 6 & 1 \\
\hline FC & & 7 & 3 & 1 \\
\hline LOBC & & 6 & 2 & 4 \\
\hline FLOBC & 3 & 38 & 13 & 1 \\
\hline HKFSC & 11 & 22 & 11 & 1 \\
\hline NPC & 3 & 7 & 3 & \\
\hline
\end{tabular}

The followings are some representative examples from the reference corpora:

Verb+object

two broad guidelines, we shall continue to makeefforts in the following tasks: (a) our infrastructural development, we should makeefforts in the related planning and 
$V e r b+$ det. $/$ mod. + object

to standards and expectations, or who made exaggerated efforts to achieve these goals.

second he turned his eyes. He seemed to make no effort to speak or even smile. Presently

and in face of falling prices, we have made strenuous efforts to rationalise our

and his Foreign Minister made great efforts to curb Tirpitz and smooth British

Verb + det./mod. + mod. + object

over from Georgi Zaroubin, he made a determined effort to change this idea.

and saucepan drop from his hands,makes diverse convulsive efforts to rise, and finding

Other

Only four towns indicated that they made any more than a normal effort to list property

loving him; from the tension, the weariness that made even breathing an effort.

We in the HKMA have taken the initiative and made a start in this effort, and have got quite a lot

competitive market. At the same time, we have made significant progress in our efforts to improve

As observed in the NPC, Verb + det. /mod. + object was the canonical configuration function in all the reference corpora.

Analysis of the second positional variation of the concgram (i.e., effort(s) made)

In comparison to make effort, effort made was significantly more frequent in the NPC corpus as there were 392 stances of this positional variation. Table 5 presents the configurations of this variation.

Table 5. The configurations of effort made in the NPC

\begin{tabular}{|c|l|c|}
\hline \multicolumn{1}{|c|}{ m.N. } & \multicolumn{2}{c|}{ Frequency } \\
\hline 1. & effort made & 36 \\
\hline 2. & effort* made & 44 \\
\hline 3. & effort $* *$ made & 256 \\
\hline 4. & effort*** made & 39 \\
\hline 5. & effort**** made & 5 \\
\hline 6. & effort***** made & 3 \\
\hline 7. & effort******made & 3 \\
\hline
\end{tabular}

Table 6 shows the comparison of textual configurations of the second positional variation of the concgram in the NPC corpus with those in the reference corpora. 
development. In spite of the efforts made in the past to ensure people's participation of has been overlooked and not much effortis made towards involving the users in constructionis not adequate. 8. Adequate effortis not made for the development and extension of appropriate to achieve this goal, all the efforts to be made by the government in economic, political, determination is imperative. Big effort must be made on domestic front for mobilization of internal, This shows that every possible effort has to be made at the government level for the mobilisation of No coordinated effort has so far been made to see that the prescribed syllabus is adhered education. (3) Efforts should be continued to make Sanskrit education timely, socially beneficial ineffective, efforts in that direction will be made afresh with a change of emphasis. The emphasis of the efforts and achievements in the country made in this short duration, some thought provoking efforts for industrial development have been made in preceding years, even with the mentioned

Table 6. The comparison of the configuration of effort made

\begin{tabular}{|l|c|c|c|c|c|c|}
\hline & $\begin{array}{c}\text { effort } \\
\text { made }\end{array}$ & $\begin{array}{c}\text { effort* } \\
\text { made }\end{array}$ & $\begin{array}{c}\text { effort ** } \\
\text { made }\end{array}$ & $\begin{array}{c}\text { effort *** } \\
\text { made }\end{array}$ & $\begin{array}{c}\text { effort }(* * * * \text { or } \\
\text { more) made }\end{array}$ & \\
\hline BC & 1 & 9 & 5 & 2 & 3 & 20 \\
\hline FC & & 2 & & & & 2 \\
\hline LOBC & 1 & 4 & 4 & 2 & & 12 \\
\hline FLOBC & 2 & 6 & 2 & & 1 & 11 \\
\hline HKFSC & 10 & 17 & 26 & 2 & 8 & 63 \\
\hline NPC & 36 & 44 & 256 & 39 & 11 & 392 \\
\hline
\end{tabular}

The comparison shows that effort* made (with two intervening words) is the canonical configuration form. However, the frequency of this configuration is noticeably high in the NPC and HKFSC than in other reference corpora. It seems that the form effort ${ }^{* *}$ made is used frequently in policy documents. However, further research is required to verify this claim. Table 7 presents the configuration functions of the second positional variation.

Table 7. The configuration functions of second positional variation in the NPC

\begin{tabular}{|c|l|c|}
\hline S.N. & \multicolumn{1}{|c|}{ make effort } & Frequency \\
\hline 1 & Noun (PrepP) + past participle & 36 \\
\hline 2 & Noun + to infinitive & 8 \\
\hline 3 & $\begin{array}{l}\text { Sub + is/am/are/was/were + } \\
\text { past participle }\end{array}$ & 32 \\
\hline 4 & $\begin{array}{l}\text { Sub + Aux + (not) + (adv.) } \\
\text { +be + past participle }\end{array}$ & 333 \\
\hline 5 & Sub + aux + to be + past participle & 11 \\
\hline
\end{tabular}

What follows is the brief description of the configuration functions described in Table 7. Noun (post modifier) + past participle [efforts (of the government) made]: In this case, made is a participle adjective post modifying the noun effort. If we examine further, the past participle form is an example of a reduced clause (e.g., efforts -that are-made). As can be seen in the second example, there can also be a prepositional phrase in between the oun and the participle form. 
first attempt towards organizational efforts made in the planned development of tourism, in Nepal. the many efforts at privatization made in the past were unsuccessful. After the

Noun + to infinitive (effort to make): In this case, to-infinitive form functions as the post modifier of the noun effort (s).

them as part of the ceaseless effort to make educational administration more efficient and and political context, and lack of effort to make it timely. Lack of comprehensiveness in teacher be reviewed from time to time in an effort to make them capable of fulfilling an increasing needs Situation (a) Culture Efforts to make local agencies and users' groups participate in

Sub + Aux (is/are/was/were) + (not) + past participle: This is one of the frequent configuration functions in the NPC corpora. In this case, the word effort functions as the subject of the passive clause. Among different forms of be verbs, were was the most frequent one (were- 25 times, was- 3 times, is- 3 times, are- 3 times). As is evident in the examples below, such forms can be negative, however, they were less frequent than the positive ones.

order to achieve this objective, an effort is made to present the distribution of the languages in of current capacities alone. An effort was made to estimate the resource requirements on a of overstaffing continues. Unless efforts are made to install cost-effective administrative Some institutional and procedural efforts were made during the Eighth Plan in order to make is not adequate. 8. Adequate effort is not made for the development and extension of appropriate on the scale, unless, timely efforts are not made to raise them tip. Priority should be given to noticed that sufficient efforts were not made in the area of agricultural prices and market that efforts to increase production should be made all $t$ he more extensive in view of population

$\mathrm{Sub}+$ modal/be/have $+(\mathbf{a d v})+.($ not $)+$ be/been/being + past participle: This is the most frequent configuration functions of the second positional variation (i.e. effort made). Table 8 presents the variations within this configuration function.

Table 8: Sub + modal/be/have $+($ adv. $)+($ not $)+$ be/been/being + past participle

\begin{tabular}{|c|l|c|}
\hline S.N. & \multicolumn{1}{|c|}{ Form } & Frequency \\
\hline 1. & Sub (post modifier) + will + (adv.) + be + past participle & 176 \\
\hline 2. & Sub (post modifier) + has/have/had + (adv.) + (not) + been + past participle & 55 \\
\hline 3. & Sub (post modifier) + shall/should + be + past participle & 21 \\
\hline 4. & Sub (post modifier) + is/are + being + past participle & 12 \\
\hline 5. & Sub (post modifier) + is/are/have + to be + past participle & 11 \\
\hline 6. & Sub (post modifier) + must be + past participle & 4 \\
\hline 7. & Sub (post modifier) + would be + past participle & 1 \\
\hline
\end{tabular}


The followings are some examples of the different configuration functions presented in Table 8.

wise basis. 9. Especial efforts will be made to implement programs, with the cooperation of the will be prohibited. Effort will also be made to make the people aware of the disastrous tax system, 4.Meaningful efforts have not been made to ensure adequate returns to the increasing addition to these, some efforts have also been made in the construction of suspension bridge, wooden been pointed out that further efforts should be made in the coming plans for boosting the general sources. To solve this problem effort is being made to tap the ground water resources. After potential embodied in them. Efforts are being made to fulfill such commitments from the government determination is imperative. Big effort must be made on domestic front for mobilization of internal

Sub $+a u x+$ to be + past participle (some representative examples):

of Internal resources Great efforts have to be made for the mobilisation of additional resources to been realised that more efforts have to be made towards achieving targets of woman and child In view of the situation, efforts are to be made henceforth for the proper arrangement in

The configuration functions of effort made identified in the NPC were compared with such functions in the reference corpora (see Table 9).

Table 9. The comparison of the configuration function of effort/make

\begin{tabular}{|l|c|c|c|c|c|c|c|}
\hline \multicolumn{1}{|c|}{ Form } & BNC & BC & FC & LOBC & FLOBC & KHFSC & NPC \\
\hline Noun + past participle & 5 & 1 & & 1 & 2 & 10 & 36 \\
\hline Noun (PrepP)+ to infinitive & 5 & 2 & & 2 & 2 & 11 & 8 \\
\hline $\begin{array}{l}\text { Sub + is/am/are/was/were + } \\
\text { (adv.) + past participle }\end{array}$ & 15 & 9 & 5 & 4 & 7 & 7 & 37 \\
\hline $\begin{array}{l}\text { Sub + Aux + (not) + (adv.) } \\
\text { +be + past participle }\end{array}$ & & & & & & 23 & 333 \\
\hline $\begin{array}{l}\text { Sub + aux + to be + } \\
\text { past participle }\end{array}$ & 3 & 1 & 1 & 1 & 1 & & 11 \\
\hline Sub + finite clause & & & & & & 9 & \\
\hline
\end{tabular}

The comparison also shows that the same configuration function Sub (PreP/and noun) infinitive clause $)+A u x+(n o t)+(a d v)+.b e+$ past participle was the canonical configuration function. However, the use of this function only in the NPC and HKFC seem to suggest the frequent use of this configuration function in policy documents. Followings are some representatives examples taken from reference corpora: 


\section{Noun+ past participle}

immensely encouraged by the splendid effort made, particularly by our own British it may have. And I am pleased that the efforts made by Hong Kong as a whole have been duly

\section{Noun $+($ PrepP $)+$ to + verb}

new Brahms Second is a major effort to make a record that sounds like a real orchestra rather) efforts of the Home Office and the police to make the public more aware of the need to community support for all of our efforts to make Hong Kong a better place to live. This is an

\section{Sub + Aux (is/are/was/were) + (not) + past participle}

training programs for those skills. No effort is made in the same studies to present practical plans and strenuous efforts are made to keep them in the active fellowship. it is not surprising that many efforts were made to give it concrete expression. A number Some time ago an effort was made to sell more yoghurt in greater

\section{$\mathrm{Sub}+$ modal/be/have $+(\mathrm{adv})+.($ not $)+$ be/been/being + past participle}

sewer maintenance division said efforts will be made Sunday to clear a stoppage in a sewer Within each chapter an effort has been made to group together those crystals with similar (5)__Unsuccessful efforts have been made to replace high mileage allowances with state in the extensive efforts President Kennedy has made to enlist solid bipartisan support for side every conceivable effort had been made to arrive at agreement on a procedure for the where a major Soviet effort is being made. But the issue is also a basic disagreements occur every effort should be made to resolve the issue and to avoid dissention. with systemic consequences. So efforts must be made to strengthen global prudential and regulatory

\section{Sub + finite clause}

years of premium payments. The efforts you make now and over the next few years will assure you and sponsors for your superb efforts that make this event a huge success. I look forward to organisations. Your hard work and efforts have made this event a great success. And, of course, my is the result of the tremendous efforts we have made to maintain and, where practicable, improve our our shared view of the efforts that must be made by businesses, governments and consumers, to to the painstaking efforts which have been made over the years to develop and agree operational of the efforts that our community has made since the Asian financial crisis. The United I applaud the efforts of all those who helped make this important agreement possible, in for the extra effort many of you have had to make to come here today. It's a privilege and a for the efforts and the contributions they have made in this momentous year. Guo Shuqing 
As indicated in Table 10, the concgram make effort seems to be common in discourse related to policy and plans because the normalized frequency of its occurrence is noticeably high in the NPC and HKFC.

Table 10. Normalization of frequency of make/effort in different corpora

\begin{tabular}{|l|l|l|l|l|l|l|} 
& \multicolumn{1}{|c|}{ BC } & FC & \multicolumn{1}{|c|}{ LOBC } & FLOBC & KHFSC & \multicolumn{1}{|c|}{ NPC } \\
\hline $\begin{array}{l}\text { Number of words } \\
\text { in corpora }\end{array}$ & $\mathbf{1}$ million & $\mathbf{1}$ million & $\mathbf{1}$ million & $\mathbf{1}$ million & $\mathbf{7}$ million & 2 million \\
\hline $\begin{array}{l}\text { Concgrams per } \\
10,000 \text { words }\end{array}$ & 0.35 & 0.13 & 0.21 & 0.2 & 0.82 & 2.18 \\
\hline
\end{tabular}

Collocation, sematic preference, and semantic prosody of make/effort

Collocations: Table 11 shows the adjectives, nouns and verbs that frequently collocated with effort(s) in the corpora used in this research.

Table 11. Collocates of effort(s)

\begin{tabular}{|l|l|l|l|l|l|}
\hline \multicolumn{5}{|c|}{ Adjectives } & \multicolumn{2}{c|}{ Nouns } & Verbs \\
\hline active & cooperative & greater & possible & alleviation & initiate \\
\hline addition & coordinated & increased & present & background & intensify \\
\hline additional & coordinating & institutional & private & community & made \\
\hline alleviation & decentralization & integrated & reasonable & conservation & make \\
\hline collaborative & determined & necessary & recent & coordination & making \\
\hline collective & developmental & joint & repeated & decontamination & meet \\
\hline community & effective & limited & serious & defense & plan \\
\hline concentrated & established & local & significant & development & \\
\hline concerted & extensive & marketing & special & education & \\
\hline considerable & further & national & strenuous & future & \\
\hline consistent & future & particular & sustained & government & \\
\hline continued & genuine & past & timely & initiative & \\
\hline continuing & governmental & persistent & tremendous & management & \\
\hline continuous & great & planned & targeted & mobilization & \\
\hline
\end{tabular}


Semantic preference: Semantic preference refers to the semantic field that the collocational words belong to. In this case, the word effort has semantic preference to verbs of making or changing (e.g., make, develop, plan, increase); adjectives of difficulty (e.g., special, coordinated, continued), and noun with institutional sense (e.g., development, government). The word effort was in common use in the plan and policy documents when concrete implementation strategies to achieve the desired goals were lacking.

Semantic prosody: Semantic prosody refers to negative or positive orientation of meaning of an MSU. The construction make effort has a nuance of negative semantic prosody as it has the meaning of doing something good to change or improve the existing situation when the plan for concrete action is lacking. See the examples below:

much more data is needed. Efforts will be made together as much data as possible.

Plan: Increase in Exports Efforts will be made to increase exports by 100 percent within the on imported materials, continued efforts will be made to replace imports by domestic production by and wasteful expenditures. Efforts will be made to change all sectors of the country's economy

The detailed reading of the text where the above sentences were used showed that there were no specific targets set and no implementation plans to replace imports by domestic production, increase exports by 100 percent and change all sectors of the economy. Similarly, words like special, earnest, rational, continued, necessary, coordinated, additional, and possible that collocated with effort carried the sense that achieving the desired goal was not easy. The predominant use of effort in a passive structure with no responsible agent makes the lack of action apparent.

\section{Conclusion}

This study has examined the phraseology of a two-word concgram. The analysis shows that make/effort constitutes an MSU. The second positional variation (i.e. effort made) is more common than the first positional variation (i.e. make effort). The MSU has the semantic preference for verbs of change (e.g., make, develop, change), noun having organizational sense (e.g., nation, government, institution) and adjectives associated with difficulty and time duration (e.g., special, coordinated, continued). It has negative semantic prosody of difficulty and seems to be mostly used in passive constructions without agents. As there are no implementation plans to achieve the goals and the agency that makes efforts is usually obfuscated, the responsible ones 
are difficult to identify and/or held accountable. Therefore, plans for making efforts do not necessarily make a difference.

\section{Implications of the study}

Corpus linguistics has multiple benefits in language teaching (Ebeling, 2009). However, its use in language teaching is still rare and "teachers are still unwilling to or lack the skill to use corpora as an aid to get new insights into English" (Aijmer, 2009, p. 1). In the context of Nepal, though corpus linguistics forms a part of the University Curriculum in English, students are rarely offered hands-on experiences (Granath, 2009). Highlighting its importance, Granath (2009) calls corpus a native-speaker consultant and considers corpus even more informative than a dictionary or a grammar book. Corpus can also be used for designing teaching materials and exploring texts produced by second language learners. Granath (2009) suggests that "different types of corpus exercises can profitably be made part of regular foreign language courses" (p. 48).

Corpus informed teaching can introduce learners with real language rather than madeup examples. Teachers can use corpora to create teaching materials, demonstrate variation in grammar, and show contextual variations in meaning. Corpora can help teachers present a contrastive analysis of lexical items in different domains, teach the meaning of multiword units, and use corpus as a reliable tool to answer students' questions related to the use of language. Alternatively, teachers can ask students to draw their own conclusions based on corpus data (Adolphs, 2006; Ebeling, 2009; Granath, 2009; McEnery \& Hardie, 2012; Römer, 2009). According to Adolphs (2006), three main implications of corpus analysis in language teaching are syllabus design, material development, and data-driven learning (Adolphs, 2006). For this reason, it is better to introduce corpus analysis in pre- or in-service teacher training and teacher education courses so that teachers could help themselves and their students to discover the use of language and acquire knowledge and skills (Ebeling, 2009; Granath, 2009; Römer, 2009). In this regard, the analysis of concgram can help the learners to better understand the association between words, common phenomena in the English language.

\section{References}

Adolphs, S. (2006). Introducing electronic text analysis: A practical guide for language and literary studies. London: Routledge. 
Aijmer, K. (Ed.). (2009). Corpora and language teaching. Amsterdam: John Benjamins.

Biber, D., Conard, S., \& Cortes, V. (2004). If you look at...: Lexical bundles in university teaching and textbooks. Applied Linguistics, 25(3), 371-405.

Cheng, W. (2009). Income/interest/net: Using internal criteria to determine the aboutness of a text. In K. Aijmer (Ed.), Corpora in language teaching (pp. 157178). Amsterdam: John Benjamins.

Cheng, W., Greaves, C., Sinclair, J. M., \& Warren, M. (2009). Uncovering the extent of the phraseological tendency: Towards a systematic analysis of concgrams. Applied Linguistics, 30(2), 236-252.

Cheng, W., Greaves, C., \& Warren, M. (2006). From n-gram to skipgram to concgram. International Journal of Corpus Linguistics, 11(4), 411-433.

Ebeling, S. O. (2009). Oslo Interactive English: Corpus-driven exercises on the Web. In K. Aijmer (Ed.), Corpora and Language Teaching (pp. 67-82). Amsterdam: John Benjamins Publishing Company.

Granath, S. (2009). Who benefits from learning how to use corpora? In K. Aijmer (Ed.), Corpora and language teaching (pp. 47-66). Amsterdam: John Benjamins Publishing Company.

Greaves, C. (2009). ConcGram [a phraseological search engine]. Amsterdam: John Benjamins.

Greaves, C., \& Warren, M. (2007). Concgramming: A computer driven approach to learning the phraseology of English. ReCALL, 19(3), 287-306.

Gries, S. T. (2008). Phraseology and linguistic theory: A brief survey. In S. Granger and F. Meunier (Eds.), Phraseology: An interdisciplinary perspective (pp. 3-26). Amsterdam: John Benjamins. 


\section{ЏNELTA}

McEnery, T., \& Hardie, A. (2012). Corpus linguistics: Method, theory and practice. Cambridge: Cambridge University Press.

Rayson, P. (2008). From key words to key semantic domains. International Journal of Corpus Linguistics, 13(4), 519-549.

Römer, U. (2009). Corpus research and practice: What help do teachers need and what can we offer? In K. Aijmer (Ed.), Corpora and language teaching (pp. 83100). Amsterdam: John Benjamins Publishing Company.

Scott, M. (2012). WordSmith Tools version 6. Lexical Analysis Software.

Scott, M., \& Tribble, C. (2006). Textual patterns: Key words and corpus analysis in language education / Mike Scott and Christopher Tribble. Amsterdam: John Benjamins.

Sinclair, J. M., \& Carter, R. (2004). Trust the text: Language, corpus and discourse. New York, N.Y: Routledge.

Stubbs, M. (2005). Conrad in the computer: Examples of quantitative stylistic methods. Language and Literature, 14(1), 5-24.

Stubbs, M. (2007). Collocations and semantic profiles: On the cause of the trouble with quantitative studies. Functions of Language, 3, 166-193.

Tognini-Bonelli, E. (2001). Corpus linguistics at work. Amsterdam: John Benjamins.

Warren, M. (2009). Why concgram? In C. Creaves, Concgram 1.0: A phraseological search engine (pp. 1-11). Amsterdam: John Benjamins. 
